strongly curved paralobi are linked by an altitudinal cline to those with moderately curved paralobi. This alternative will be tested by further collecting.

A full report of this work will be published in due course. I am indebted to Prof. G. Saccà for help in various ways.

South African Institute for Medical Research, Johannesburg. May 23.

1 Sacca, G., and Rivosecchi, I., Rend. Accad. Naz. Lincei (Classe di
Scienze flsiche, matematiche e naturali) (8), $19(6), 497$ (1955). ${ }^{2}$ Mayr, E., "Advances in Genetics", 2, 234 (1948).

\section{Occurrence of Polydora pulchra Carazzi in British Waters}

WHILE studying the seasonal variation in plankton and hydrography of the plaice ponds at the Marine Biological Station, Port Érin, I came across a dense population of larvæ belonging to the species Polydora pulchra Carazzi (Polychaeta Spionidae). The identification is based on the key, descriptions and figures given by Hannerz'. The identification was further confirmed when the larvæ metamorphosed in the laboratory.

Carazzi $^{2}$ was the first to describe pulchra as a variety of Polydorc antennata Claparède; but recently Hannerz ${ }^{1}$ separated the variety and classed it as a distinct species with the name Polydora pulchra Carazzi. There are no previous records of either Polydora antennata or Polydora pulchra in British waters (Tebble, N., personal communication). Adult specimens have not yet been found in British wators.

Polydora pulchra has been very rarely reported. The only records are those of Fauvel ${ }^{2}$ and Hannerz ${ }^{1}$. Fauvel found the species in the Mediterranean at Naples and in the Atlantic off northern Spain, while Hannerz found three individuals in southern Sweden. The occurrence of Polydora pulchra at Port Erin thus extends the known distribution of the species into the Irish Sea. Observations on the behaviour of the larvæ of Polydora pulchra and their resistance to changes in temperature, $p \mathrm{H}$ and salinity are being published elsewhere.

I wish to thank Dr. N. S. Jones, of Port Erin, and Mr. Norman Tebble, of the British Museum (Natural History), for confirmation of the identity of the larvæ.

Marine Biological Station,

Port Erin, Isle of Man. July 25.

1 Hannerz, L., Zoologiska, 31 (1956).

${ }^{2}$ Carazzi, D., Zool. Stat. Neapel. Mitt., 11 (1895).

'Fauvel, P., "Faune de France", 16, "Polychetes sedentaires" (1927).

\section{An Unusual Method of capturing Prey by a Cuttlefish}

IT is usually assumed that the typical shallow-water decapod cephalopods are active hunters and seek out their prey rather than wait for the prey to come to them. It does sometimes occur ${ }^{1}$ that a cuttlefish is lying passive, half buried in the sea bottom, and that when food, such as a prawn or a crab, passes close by, the tentacular arms are rapidly unfurled in an attempt to secure the prey. In contrast to these methods, I was fortunate enough to observe a cuttlefish actively luring fish to within reach of the tentacular arms.
The observation was made in the late afternoon in the Straits of Singapore, some six miles offshore, from the Fisheries Research Station's launch, the Chermin, during the interval between two of the routine series of plankton hauls which are made in this area. At the time, the engine was shut off and the boat was drifting with the tide in a fairly extensive patch of Sargassum weed. The sea was glass-calm.

Through a break in the weed a small cuttlefish of about six inches length could be seen, floating some twelve inches below the surface. It was lying horizontally, the arms typically bunched together, there being no sign of any movement except from the suckered tips of the tentacular arms. These were extended above the head, inclined slightly forward, straight, excepting the distal suckered portions, and were slightly divergent. Both the tips of the tentacular arms were pendulous and slowly waving about in the water. Since the water was so perfectly calm, and there being no movement of any part of the submerged fronds of the Sargassum weed, it is reasonable to assume that the cuttlefish was waving them. This assumption is supported by the distribution of colour over the body. All the body, excepting the suckered areas of the tentacular arms, was of a uniform dull brown colour, very similar to that of the Sargassum weed. The suckered areas of the tentacular arms were white and very prominent.

It should be added here that I am well acquainted with the appearance of moribund and dying cuttlefish, and the possibility of the cuttlefish discussed here being moribund was considered, and rejected, since there was no indication whatever of it being other than healthy and normal in its behaviour.

Several times during some ten minutes of observation, small fish, which were clustered under the Sargassum weed, left their place of shelter to investigate the white tentacle tips. When the fish approached close to the tentacular arms, the cuttlefish attempted to catch them by a sudden dart forwards and securing them with the arms. During the period of observation the attempts were, unfortunately, unsuccessful. The cuttlefish did not exhibit any colour changes when approached by the fish, or when attempting to catch them.

Thus, although the actual capture of the prey was not observed, it was an undoubted case of an animal, accepted as being a hunter of its prey, deliberately and successfully luring its prey to it.

\section{Singapore Regional Fisheries Research Station, \\ Singapore 17. May 21. \\ ${ }^{2}$ Wilson, D. P., J. Mar. Biol. Assoc., 26, 421 (1944-47). \\ Influence of Gamma Irradiation on the Breeding Affinities of Lolium perenne and Festuca pratensis \\ J. WICKSTEAD}

I HAVE recently carried out investigations to determine the possible influence of gamma irradiation on the breeding affinities of Lolium perenne and Festuca pratensis. These two diploid species have hitherto been considered to be extremely ineompatible $^{1}$, although it so happens that during these investigations a number of highly compatible genotypic combinations were found. I was indeed fortunate to have worked with parental material which on crossing showed four distinct levels of 